\title{
Mothers Against Decapentaplegic Homolog 3
}

National Cancer Institute

\section{Source}

National Cancer Institute. Mothers Against Decapentaplegic Homolog 3. NCI Thesaurus. Code C18034.

Mothers against decapentaplegic homolog 3 (425 aa, $48 \mathrm{kDa}$ ) is encoded by the human SMAD3 gene. This protein plays a role in the modulation of transforming growth factor (T GF)-beta-mediated signaling and gene expression. 